Research Article

\title{
Shaking Table Test of Seismic Response of Immersed Tunnels under the Influence of Multiple Factors
}

\author{
Zhiyong Ouyang $\mathbb{D}^{1}{ }^{1}$ Jie Cui, ${ }^{2}$ Ruofan Luo, ${ }^{1}$ and Peijie Li ${ }^{1}$ \\ ${ }^{1}$ College of Civil Engineering, Jiaying University, Meizhou 510405, China \\ ${ }^{2}$ School of Civil Engineering, Guangzhou University, Guangzhou 510006, China \\ Correspondence should be addressed to Zhiyong Ouyang; 52424848@qq.com
}

Received 2 May 2020; Revised 31 August 2020; Accepted 30 September 2020; Published 20 October 2020

Academic Editor: Mohammad Rafiee

Copyright (C) 2020 Zhiyong Ouyang et al. This is an open access article distributed under the Creative Commons Attribution License, which permits unrestricted use, distribution, and reproduction in any medium, provided the original work is properly cited.

\begin{abstract}
To explore the dynamic characteristics and influencing factors of immersed tunnels under the action of earthquakes, 5 groups of shaking table model tests were carried out. Three different site conditions (unsaturated sand site, homogeneous saturated sand site, and nonuniform site), structural stiffness, and seismic wave input direction were considered. By comparing the above influencing factors, the seismic response law affecting the immersed tunnels was obtained. The test results show that, under the action of horizontal earthquakes, the liquefaction of sand and the larger tunnel stiffness may influence the acceleration development of the soil layers; seismic wave input directions affect the excellent frequency and frequency range of the soil layers, and the liquefaction of sand and large structural stiffness change the shape of the Fourier spectrum curve of the soil layers; site conditions, structural stiffness, and seismic wave input direction have a significant effect on the internal forces of tunnels. Normally, the strain in the heterogeneous soil layer under the horizontal seismic wave input is the largest, and the peak strain of the upper side of the tunnel side wall and center column is larger than the lower part, while the mechanism of structural damage caused by vertical earthquakes is different.
\end{abstract}

\section{Introduction}

At present, the main methods for tunnel construction include shield tunneling and immersed tube [1,2]. In the water environment, the immersed tunnel method has become the first choice for the construction of water tunnel in the world due to its strong adaptability, high structural reliability, simple construction, and little impact on traffic during construction. But immersed tunnels in the water environment, located in a complex environment, are prone to damage under large dynamic loads, especially earthquake loads. Once the damage occurs, the consequences are unimaginable. Therefore, it is of great significance to study the dynamic characteristics and influencing factors of the immersed tunnels under earthquake loads. Nowadays, there are three methods widely used to study the seismic performance of immersed tunnels, namely, prototype observation, theoretical analysis, and experimental research. Due to the particularity of their geographical locations, Japan and the United States have done a lot of research on prototype observation, obtaining some measured seismic data and research results of inland underground structures and superstructures [3-5]. Immersed tunnel is a new type of structure, around which the environment is diverse (the geographical environment of different countries in the world is quite diverse). Besides, the amount of damage caused by earthquakes, which happens accidentally, is small. Therefore, comprehensive and detailed seismic observation data are quite limited, which makes it difficult to understand the failure mode of immersed tunnels. With the development of seismic theory and computer technology, the theoretical analysis method has become one of the main methods to study the seismic performance of immersed tunnels. There are two main theoretical analysis methods presently. One is the simplified analysis method, and the other is the numerical analysis method. These two methods enable repeated 
study of different problems of underground structures with less cost, so they are widely applied in the performance analysis of underground structures [6-15]. However, they may bring about some problems in some cases. For example, there are some problems in most of the existing simplified analysis methods: (1) The theories are mostly based on the seismic analysis methods of ground structures or summarized from the seismic damage of underground ones, lacking strict theoretical basis. (2) It is difficult to accurately determine the earthquakes loads and their application mode. (3) Complex soil layers and structural forms have a great influence on the accuracy of calculation. (4) The methods to solve the calculation parameters are too diverse to ensure their accuracy. As for the numerical analysis methods, calculation personnel with excellent theoretical basis and high standards of selection of structural calculation parameters and models are required, which are prone to human influence. Shaking table model tests could reproduce the seismic process of underground structures rapidly, enabling researchers to intuitively understand the seismic response law and failure mechanism of underground structures. That is why they are widely used. For example, the shaking table test was first applied by Okamoto and Tamura to study the dynamic characteristics of underwater tunnels, yielding some important conclusions in terms of the vibration characteristics and deformation characteristics of underwater tunnels [16]. Chen et al. conducted multiple shaking table tests on subway stations under different conditions and figured out the effects of deep and weak ground, near-field vibration, and far-field vibration on subway stations $[17,18]$. Zhang et al. conducted a multipoint shaking table model test on super-long immersed tunnels, exploring the nonuniformly excited seismic response law of immersed tunnel models and the deformation of pipe joints [19]. Keizo et al. used the raw materials of actual engineering to create a large-scale model of underground structures and used this as a research object to conduct a large-scale shaking table test for underground structures. The interaction mechanism of the soil-underground structures and the deformation capacity of the underground structures during the large-scale deformation of the site were discussed [20]. Wang et al. concluded that the characteristics of seismic waves, wave amplitude, and water all affected the seismic response of immersed tunnel segments through shaking table tests [21]. Although many scholars have carried out shaking table model tests on various forms of underground structures, obtaining many research results, compared with other forms of underground structures, the number of shaking table model test studies of immersed tunnels is still small. In addition, most of the above studies focused on nonliquefied sites without considering the impact of the tunnel rigidity, the direction of ground motion input, and the nonuniformity of the site soil on the immersed tunnels.

In order to understand the dynamic characteristics and influencing factors of the immersed tunnels under earthquake action, taking the Hong Kong-Zhuhai-Macao submarine immersed tunnel project as the research background, a scaled model shaking table test was carried out on the immersed tunnels. In the test, factors such as site conditions, ground motion input direction, and structural rigidity were considered, and 5 groups of shaking table tests were carried out. The seismic response law of immersed tunnels was obtained by comparing the above factors.

\section{Experimental Designs}

This experiment was carried out on a large-scale three-dimensional simulated seismic vibration table of the Institute of Engineering Mechanics, China Seismological Bureau (Harbin). The specific parameters of the shaking table are shown in Table 1. In this test, a laminated shear model box was used, which can obviously reduce the interference of reflected waves generated by the wall of the box and has better lateral restraint on the soil. It consisted of 15 layers of steel frames, each of which can move in the horizontal direction. The overall size was the length $\times$ width $\times$ height: $3.70 \mathrm{~m} \times 2.40 \mathrm{~m} \times 1.70 \mathrm{~m}$.

2.1. Test Similarity Relation. To make the shaking table test truly reproduce the destruction process of the structure caused by earthquake action, it is necessary to make the test model and prototype as similar as possible in the test design. According to the Buckingham $\pi$ theorem and the main purpose of the test, the similarity relation of the test is mainly the structural similarity relation, and the tunnel model can meet the similarity ratio relation of density through additional artificial mass. The similarity relation can be expressed as follows:

$$
\sigma=f(\sigma, L, E, \rho, t, d, v, a, g, \omega) .
$$

Formulas such as $\sigma, L, E, \rho, t, d, v, a, g$, and $\omega$ are dynamic stress, length, elastic modulus, density, time, displacement, velocity, acceleration, gravitational acceleration, and circular frequency in turn. The length $L$, density $\rho$, and elasticity models $E$ are generally unknown. The relevant parameters of the similarity ratio of the tests are shown in Table 2 .

2.2. Model Making and Design. Given the similarity between particulate concrete and ordinary concrete, which benefits the realization of model similarity rate, the immersed tunnels in this test were made from particulate concrete and galvanized lead wires. In order to explore the seismic response law and influencing factors of immersed tunnels, factors such as unsaturated sand (dry sand) site, saturated sand site, longitudinal nonuniform site, tunnel stiffness, and ground motion input were considered, with 5 groups of tests designed. The seismic wave input of the first four groups of tests was all horizontal. The four groups were, respectively, the shaking table test of the flexible immersed tube tunnels in unsaturated sand field, saturated sand field, longitudinal nonuniform field, and test of the rigid immersed tunnels in the saturated sand field. The fifth group was the shaking table test of the flexible immersed tunnels in the saturated sand field under vertical earthquake input. In order to obtain the seismic response law of different immersed tube tunnel stiffness, two tunnel models with different stiffness were made in this experiment (the flexible tunnels with joint and the rigid tunnels without joint, which are described in detail 
TABLE 1: Technical parameters of earthquake simulation shaking table.

\begin{tabular}{lc}
\hline Indicators & Technical parameter \\
\hline Peak load & $350 \mathrm{kN}$ \\
Table size & $5 \mathrm{~m} \times 5 \mathrm{~m}$ \\
Direction of vibration & $X, Y, Z$ \\
Maximum acceleration & $X, Y: 1.0 \mathrm{~g} ; Z: 0.7 \mathrm{~g}$ \\
Maximum speed & $X, Y: 50 \mathrm{~cm} / \mathrm{s} ; Z: 40 \mathrm{~cm} / \mathrm{s}$ \\
Maximum displacement & $X, Y: \pm 8 \mathrm{~cm} ; Z: \pm 5 \mathrm{~cm}$ \\
Frequency range & $0.5 \sim 40 \mathrm{~Hz}$ \\
Maximum overturning moment & $735 \mathrm{kN} \cdot \mathrm{m}$ \\
\hline
\end{tabular}

below). To facilitate the test comparison, the design depth of the soil layer, dry density of sand, clay density, and tunnel buried depth in the five groups of tests were consistent. Soil layer parameters are shown in Table 3, with the five groups described, respectively, as follows:

(1) Test 1 was a shaking table test of a flexible immersed tunnel in unsaturated sand field under horizontal earthquake input. Firstly, the soil layers were compacted layer by layer according to the design height. When the soil layer was filled to the design depth of the tunnel, the connected flexible immersed tunnel model was placed, with the foundation soil backfilled afterwards. The flexible immersed tunnel consisted of 3 pipe sections and 2 joints. The pipe section was 0.5 meters long, 1.26 meters wide, and 0.38 meters high, with the wall being $30 \mathrm{~mm}$ thick (Figure 1(a)). A square steel plate was embedded at the port of the pipe sections to facilitate the connection between them (Figure 1(b)). Pipe section joints were generally composed of reinforced concrete shear keys and two water stops. Due to the limitation of model scale and the fact that the shear keys were easily crushed after being scaled, they could not reflect the actual shear key characteristics, so the test simplified the joints and selected natural rubber as the main material of the joints (Figure 1(c)). The cross-sectional dimension of the rubber joint was the same as that of the embedded square steel plate of the pipe section, so the assembly of the model could be completed only by connecting the steel plate of the pipe section with the rubber through bolts when splicing the pipe sections [22], as shown in Figure 1(d).

(2) Test 2 was a shaking table test of a flexible immersed tunnel in a saturated sand site under horizontal earthquake input, which shared the same site fabrication and tunnel model with test 1 . In order to fully saturate the sand, a water pipe was embedded in the inner side of the model box in the process of compacting soil, of which the water input was controlled to ensure that water could fully permeate through the sand. When the water exceeded the surface of the sand, it would be stopped and then be kept there for two days so as to fully saturate the sand. Considering a certain water depth above the immersed tunnels in reality, the water was added $230 \mathrm{~mm}$ above the surface of the sand before the experiment (Figure 2).
(3) Test 3 was a shaking table test of a flexible immersed tunnel in a longitudinally inhomogeneous site under horizontal earthquake input, which shared the same flexible immersed tunnel with test 1 . As for the distribution of the model soil layers (Figure 3), with sandy soil below the bottom of the tunnel, two soil layers with different properties, sandy soil and cohesive soil in natural state, were, respectively, arranged on two sides of the middle of the tunnel above the bottom along the longitudinal direction.

(4) Test 4 was a shaking table test of a rigid immersed tunnel in the saturated sand site under horizontal earthquake input. The rigid tunnel was $1.8 \mathrm{~m}$ long, $1.26 \mathrm{~m}$ wide, and $0.38 \mathrm{~m}$ high. Considering the stiffness of the tunnel itself and the influence of the stiffness of the tunnel joints, the wall thickness of the rigid tunnel section was $50 \mathrm{~mm}$. The model was cast at one time without joints in the middle (Figure 4(a)). After calculation, the bending stiffness (joint stiffness) of the rigid tunnel (Figure 4(b)) section was about 1.5 times as the flexible one, while the shear stiffness was about 2 times. For test 4 , the site fabrication was the same as that in test 2 .

(5) Test 5 was a shaking table test of a flexible immersed tunnel in a saturated sand site under vertical seismic input. The flexible immersed tunnel model and site soil model in test 5 were the same as those in test 2 .

2.3. Sensor Arrangement. For the purpose of comparison, sensors and observation surfaces were arranged at the same positions in the five groups of tests, as shown in Figure 5 (only the sensor arrangement and the position map of observation surfaces in test 2 are given due to the limited space). A1 to A5 were acceleration sensors on observation surface 1, with $S 1$ to $S 6$ being the structural strain gauges.

2.4. Design of Test Conditions. To study the ground motion response of the immersed tunnels under various working conditions, EL wave was selected as the external input for this test. $0.05 \mathrm{~g}$ of horizontal white noise was used for frequency sweeping after each excitation was completed, with the input horizontal direction $y$ and vertical direction $Z$ (Figure 6). The specific test loading conditions are shown in Table 4. The seismic records monitored on the table top of the shaking table were selected as analysis waves aiming to avoid the errors between the input and output of the shaking table. The EL wave measured on the table top is shown in Figure 7.

\section{Comparison and Analysis of Test Results}

To explore the dynamic characteristics and influencing factors of the immersed tunnels under earthquake action, the five groups of tests were divided into four working conditions for analysis, respectively. Case 1 was the comparative analysis of test 1 and test 2, aiming to study the influence of liquefied and nonliquefied soil layer site on the seismic response of immersed tunnels. Case 2 was the 
TABLE 2: Similitude relations and ratios of the model system.

\begin{tabular}{lcccc}
\hline Item & Symbol & Similitude relation & Tunnel ratio & Soil ratio \\
\hline Geometry & $L$ & $L_{r}$ & $1 / 30$ \\
Elasticity modulus & $E$ & $E_{r}$ & $1 / 4$ & 5 \\
Mass density & $\rho$ & $\rho_{r}$ & $1 / 30$ \\
Displacement & $D$ & $d_{r}=L_{r}$ & 1.5 \\
Acceleration & $a$ & $a_{r}=E_{r} \rho_{r}^{-1} L_{r}^{-1}$ & 0.149 \\
Time & $t$ & $t_{r}=E_{r}^{-0.5} \rho_{r}^{-1} L_{r}^{-1}$ & 6.711 & $1 / 4$ \\
Frequency & $\omega$ & $\omega_{r}=t_{r}^{-1}$ & - & $1 / 4$ \\
Pore water pressure & $u$ & $t_{r}=E_{r}^{-0.5} \rho_{r}^{-1} L_{r}^{-1}$ & - & 1 \\
Shear wave velocity & $V$ & $V_{r}$ & $1 / 4$ \\
Stress & $\sigma$ & $\sigma_{r}=E_{r}$ & $1 / 2$ \\
\hline
\end{tabular}

TABLE 3: Soil layer parameters.

\begin{tabular}{lcccccc}
\hline Name & Dry density $\left(\mathrm{g} / \mathrm{cm}^{3}\right)$ & Natural density $\left(\mathrm{g} / \mathrm{cm}^{3}\right)$ & Saturation $\left(\mathrm{g} / \mathrm{cm}^{3}\right)$ & Max shear modulus (MPa) & Water content (\%) & Plasticity index (IP) \\
\hline Sand & 1.51 & 1.84 & 2.03 & - & - & - \\
Clay & - & 1.90 & - & 14.65 & 30 & 17 \\
\hline
\end{tabular}

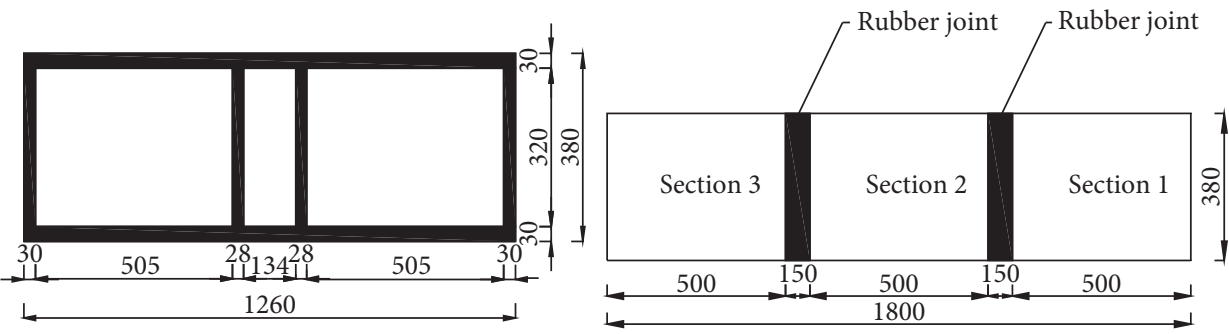

(a)

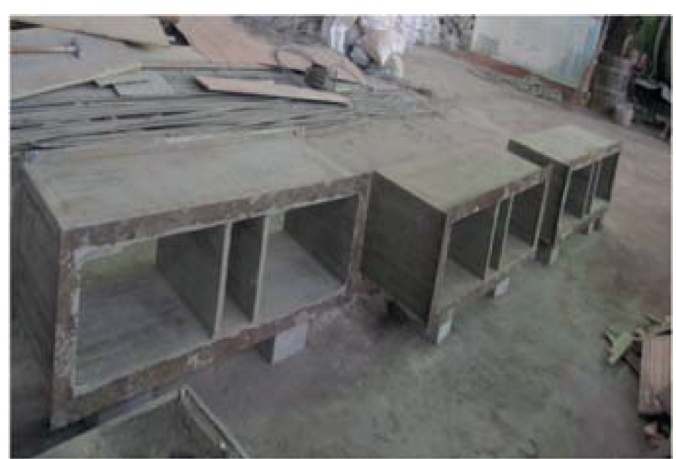

(b)

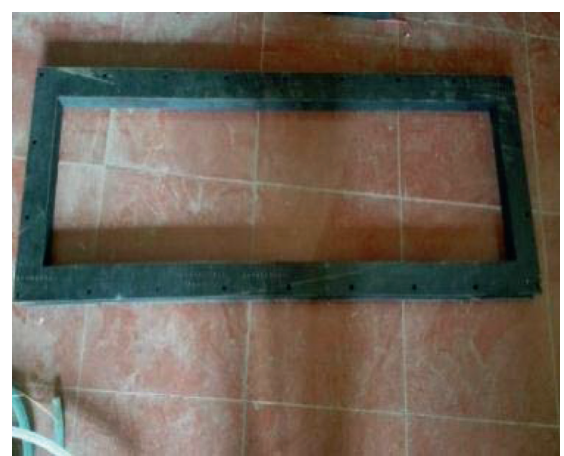

(c)

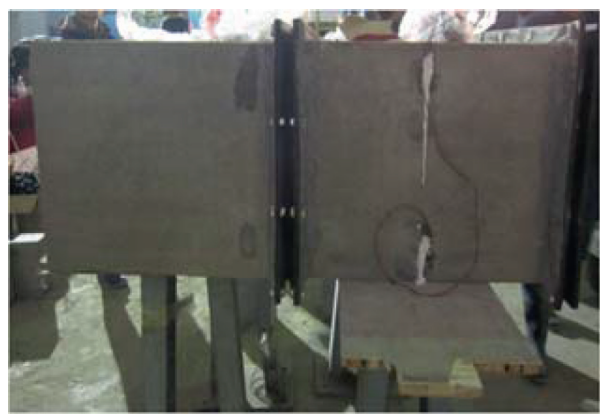

(d)

Figure 1: Test 1 structural model. (a) Tunnel cross section and vertical section dimensions (mm). 


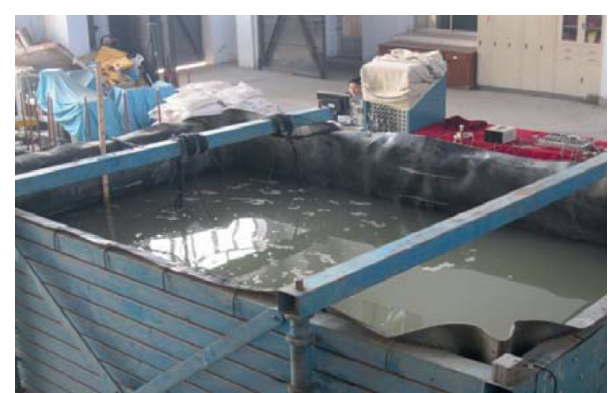

FIgURE 2: Test 2 model physical diagram.

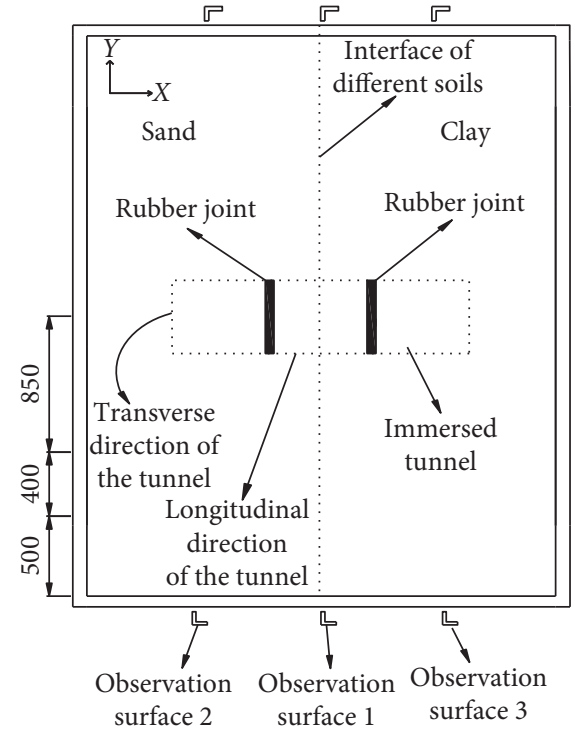

(a)

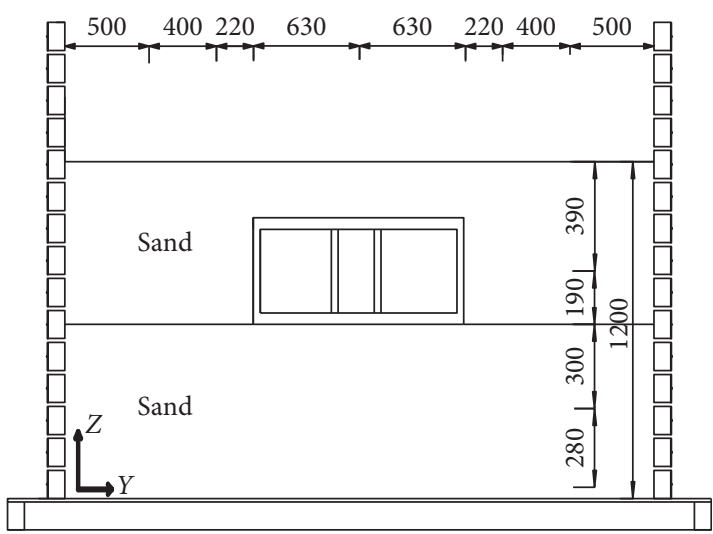

(c)

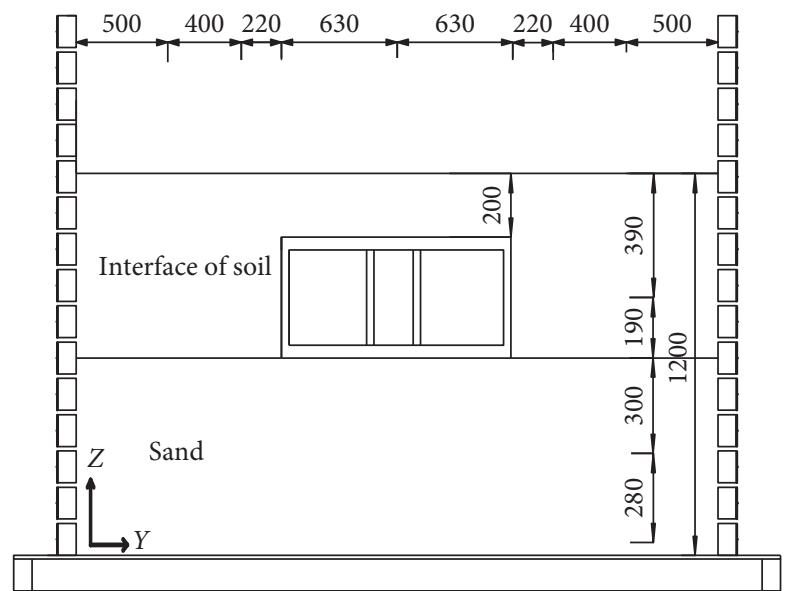

(b)

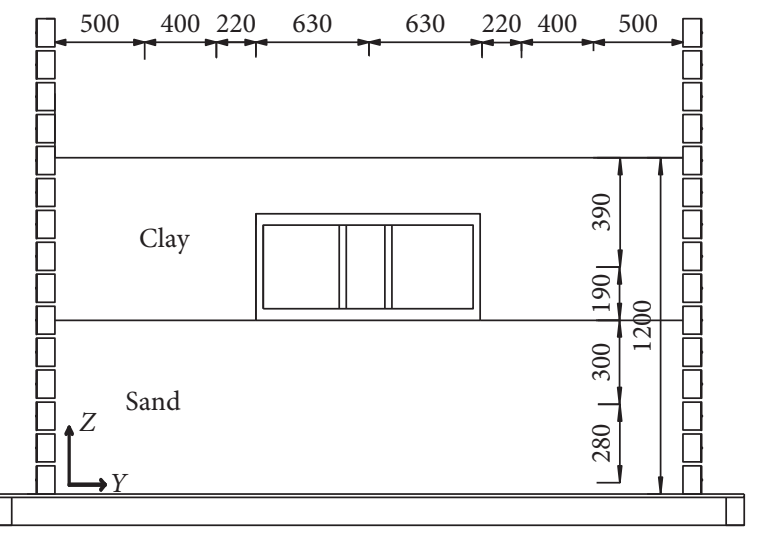

(d)

FIGURE 3: Soil layer distribution of the site. (a) Layout diagram of boundary line of soil layer and observation surface. (b) Observation surface 1. (c) Observation surface 2. (d) Observation surface 3.

analysis of test 1 and test 3 , aiming to study the influence of homogeneous and heterogeneous soil layers when they were distributed along the longitudinal direction. Case 3 was the analysis of test 2 and test 4 , aiming at the influence of tunnel stiffness. Case 4 compared test 2 and test 5 , aiming at the influence of earthquake input direction. The acceleration and the frequency spectrum of the soil layers, as well as the structural strain under the four conditions, are contrasted and analyzed as follows.

3.1. Comparison and Analysis of Test Results in Case 1. Case 1 was the comparative analysis of test 1 and test 2, aiming at the influence of liquefied and nonliquefied soil layer on the seismic response of the immersed tunnels. 

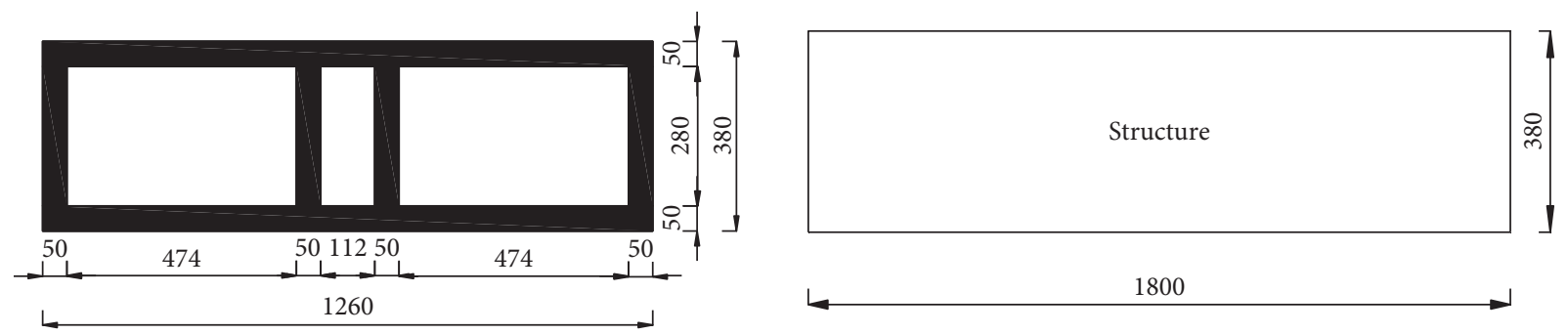

(a)
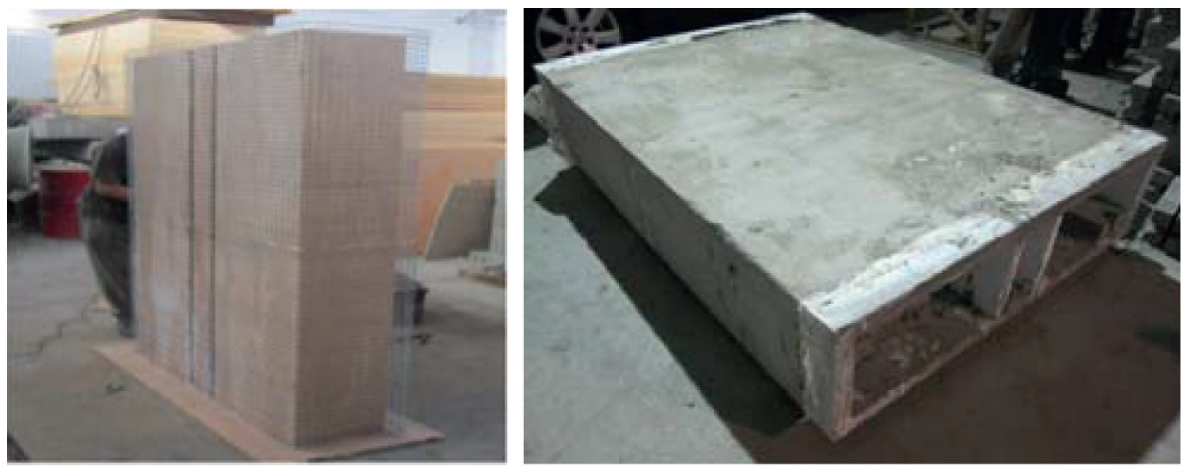

(b)

Figure 4: Test 4 structural model. (a) Dimensions of cross section and vertical section of rigid tunnel (mm). (b) Actual model of rigid tunnel.

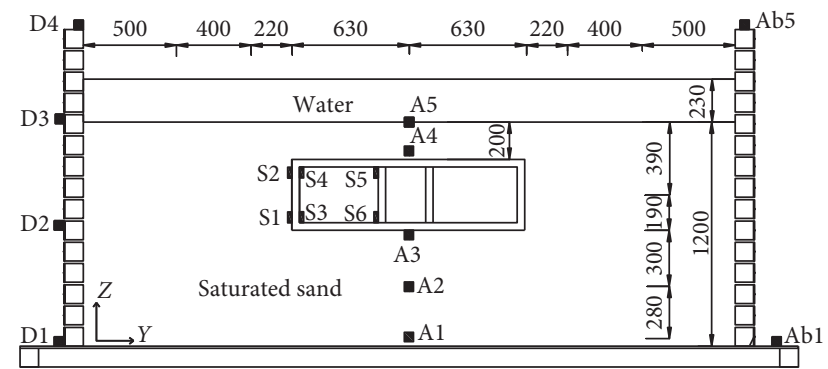

FIGURE 5: Sensor layout.

\subsubsection{Contrast Analysis of Acceleration Amplification} Coefficient. To gain the propagation law of seismic wave in nonliquefied and liquefied soil layers, the acceleration amplification coefficient at different positions was used for description, which is defined as the ratio of peak value at different displacement measuring points to that at the deepest buried depth of the model. Therefore, the acceleration peak value of $\mathrm{A} 1$ in the soil layer was taken as the reference object to define the acceleration amplification coefficients of A2, A3, A4, and A5. The acceleration amplification coefficients of the two groups are shown in Figure 8.

The following can be seen from Figure 8:

(1) Under the excitation EL wave, the acceleration amplification coefficient of soil layer in test 1 was about 1.0 1.7. When the seismic wave input amplitude increased from $0.1 \mathrm{~g}$ to $0.4 \mathrm{~g}$ gradually, the acceleration amplification coefficient increased with the decrease of the buried depth of the soil layer, and the closer to the surface it was, the greater it was, but

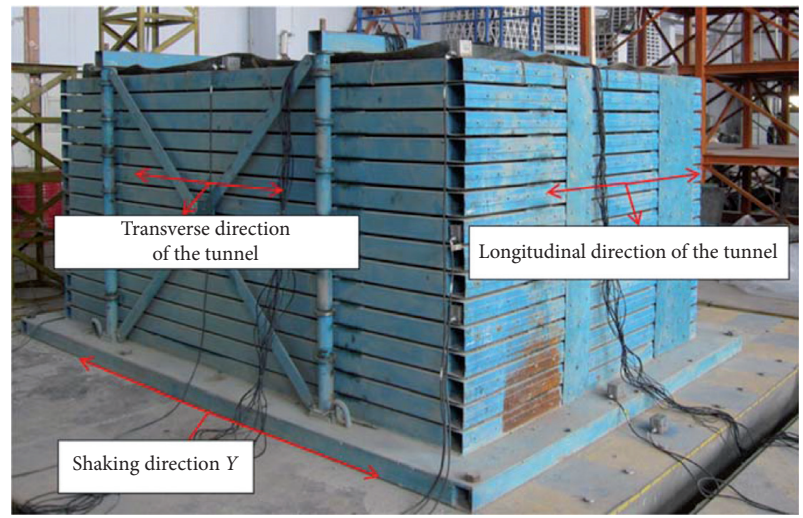

FIGURE 6: Vibration direction of shaking table.

TABLE 4: Test conditions.

\begin{tabular}{lccc}
\hline Loading order & Input wave type & Direction input & Peak acceleration $(\mathrm{g})$ \\
\hline 1 & EL-1 & $Y(Z)$ & 0.1 \\
2 & White noise & $Y(Z)$ & 0.05 \\
3 & EL-2 & $Y(Z)$ & 0.2 \\
4 & White noise & $Y(Z)$ & 0.05 \\
5 & EL-3 & $Y(Z)$ & 0.4 \\
6 & White noise & $Y(Z)$ & 0.05 \\
\hline
\end{tabular}

at the same position, it decreased with the increase of the seismic input amplitude.

(2) The acceleration amplification coefficients in test 2 ranged from 0.82 to 1.43 . When the seismic input amplitude was $0.1 \mathrm{~g}$, the pore water pressure in the 


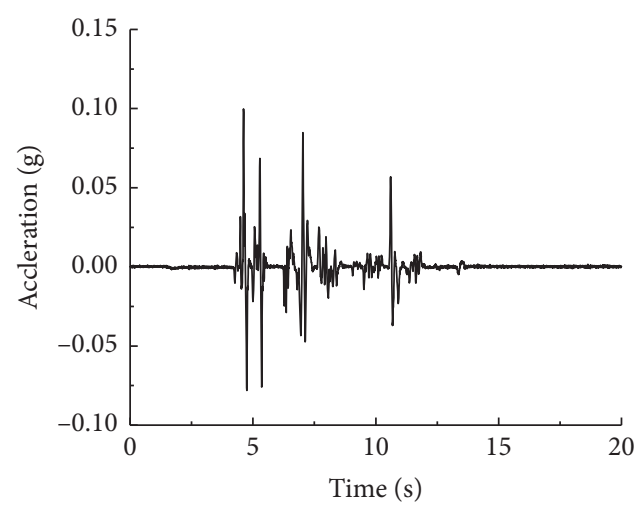

(a)

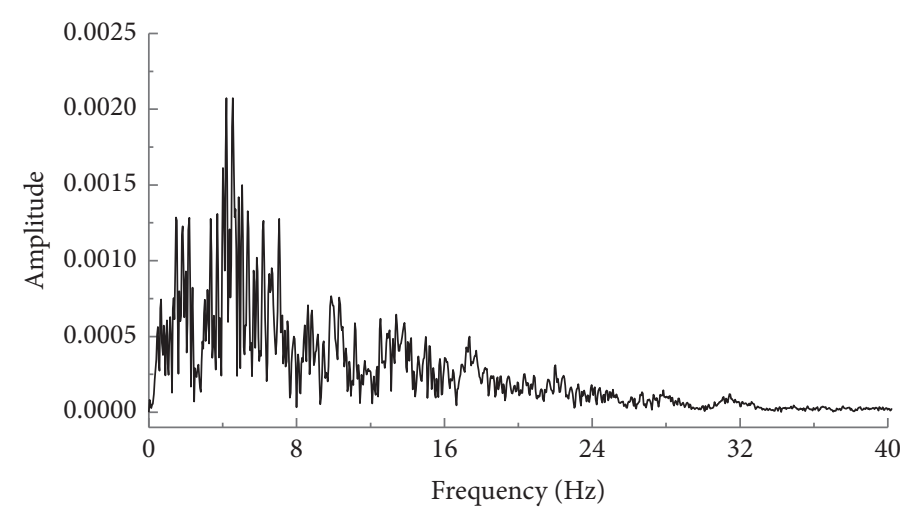

(b)

FIgURE 7: EL wave excitations during testing. (a) Acceleration process of all waves. (b) Fourier spectra of all waves.

saturated sand layer was small and the soil layer did not reach liquefaction, so the acceleration amplification coefficient increased with the decrease of the buried depth. When the input amplitude of the EL wave increased to $0.2 \mathrm{~g}$ and $0.4 \mathrm{~g}$, the pore pressure of the upper soil layer of the tunnel increased rapidly, and the soil layer liquefied, which reduced the acceleration. For the lower soil layer of the tunnel, the effective stress increased because the weight of the tunnel was larger than that of the soil layer with the same volume. Besides, the lower soil layer was restrained by the structural rigidity so that it was difficult to liquefy. That is why the acceleration amplification coefficients in test 2 increased first and then decreased with the decrease of the buried depth of the soil layer.

(3) Comparing the acceleration amplification coefficient curves of the two groups, it can be seen that when inputting EL-1 wave, the acceleration of the soil layer in the two groups shared the same development rule. However, the development rule differed between groups under excitations EL-2 and EL-3 wave. This is mainly because in test 1 no matter how large the EL wave input amplitude was, the pore water pressure would not be generated in the unsaturated sand (dry sand) site. Thereby, the effective stiffness of the soil body can be kept better in the whole vibration process. But the site for test 2 was made up of saturated sand. Only when the vibration input intensity was small would the pore water pressure generated in saturated sand be small, and the soil could maintain a large effective stiffness. However, with the vibration input intensity strength, the water pressure in saturated sand increased, and the effective stiffness of soil layer decreased. Moreover, the higher the overall liquefaction degree, the greater energy absorbed by the soil layer. The soil acceleration attenuated more obviously at that time.

Therefore, the above results indicate that the characteristics of sand (unsaturated sand sites and saturated sand

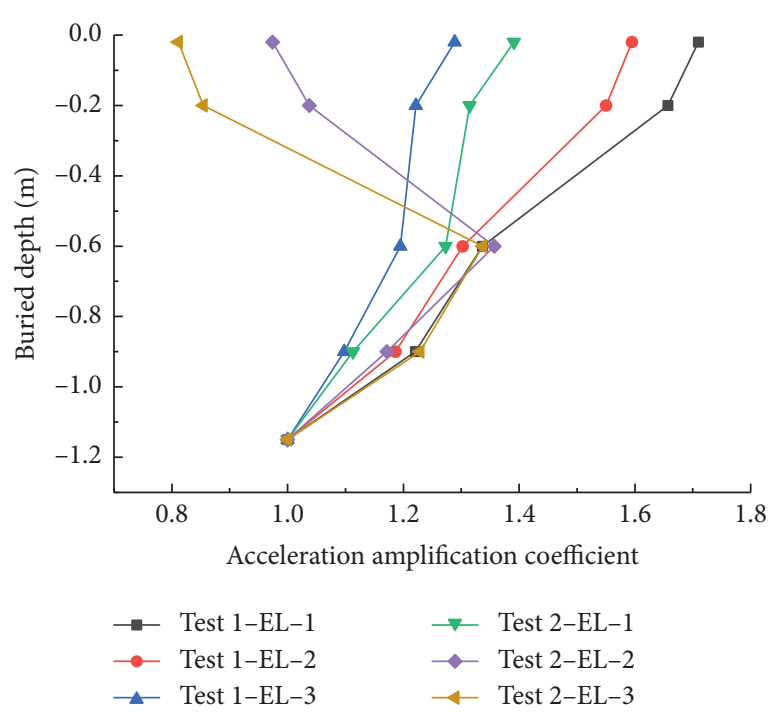

FIgURE 8: Case 1 acceleration amplification factor of soil layer.

sites) have a great influence on the propagation of seismic waves.

3.1.2. Comparative Analysis of Fourier Spectrum of Soil Acceleration. In order to explore the difference of soil dynamic characteristics between the unsaturated and the saturated sand sites, the acceleration measurement points of soil layers in tests 1 and 2 went through Fourier transformation for the corresponding acceleration Fourier spectra. The changes of their spectra in the vibration process were analyzed to judge their influence on soil dynamic characteristics. Only the acceleration Fourier spectra of each measuring point under the EL-3 seismic wave input of the two groups are contrasted and analyzed (Figure 9).

The following can be seen from Figure 9: (1) The amplitude of the Fourier spectrum of acceleration at each measuring point in the soil layer in test 1 and test 2 increased with the decrease of the buried depth of the measuring points. (2) The frequency spectrum of it in test 1 is mainly 

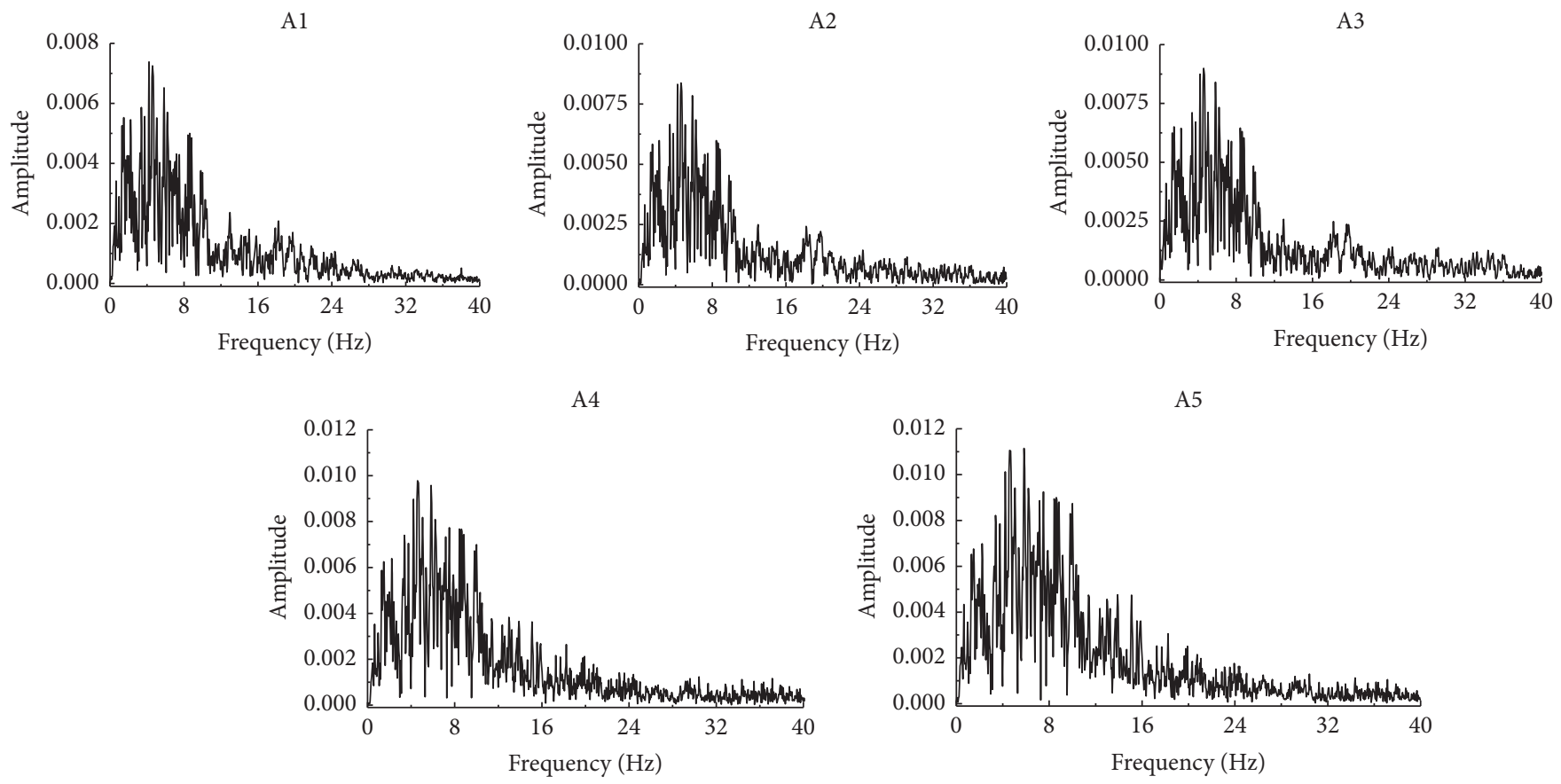

(a)
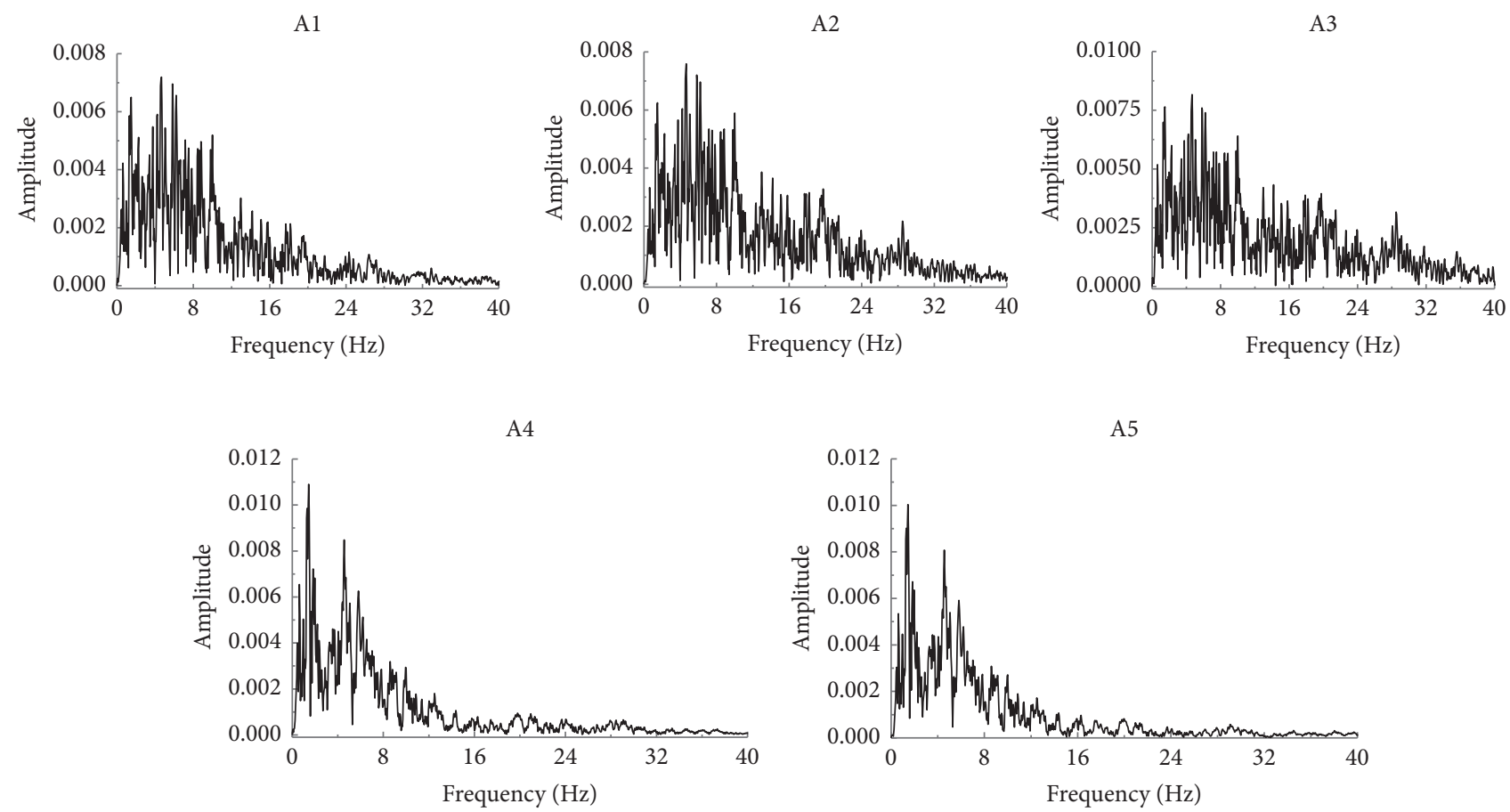

(b)

Figure 9: Case 1 Fourier spectrum of soil acceleration. (a) Test 1 accelerated Fourier spectrum of soil layer. (b) Test 2 acceleration Fourier spectrum of soil layer.

fluctuated between $0 \mathrm{~Hz}$ and $10 \mathrm{~Hz}$ but in test 2 fluctuated between $0 \mathrm{~Hz}$ and $16 \mathrm{~Hz}$, which means the range of acceleration Fourier spectrum of soil layers in test 2 was larger than that in test 1. (3) The predominant frequency of the acceleration Fourier spectrum of each measuring point in test 1 was about $5 \mathrm{~Hz}$, and the shape of the acceleration Fourier spectrum curve of each point was approximately the same. In test 2 , the predominant frequencies of measuring points $\mathrm{A} 1, \mathrm{~A} 2$, and $\mathrm{A} 3$ were about $6 \mathrm{~Hz}$, while those of $\mathrm{A} 4$ and $\mathrm{A} 5$ were about $2 \mathrm{~Hz}$, which shows that the predominant frequency reduced from $6 \mathrm{~Hz}$ to $2 \mathrm{~Hz}$ when the seismic wave propagated upward. This is because the liquefaction of saturated sand reduces the effective stiffness of the soil layer and makes the predominant frequency move from high to 
low. When saturated sand liquefies, the shape of the acceleration Fourier spectrum curve corresponding to the measuring point changes correspondingly. Therefore, the shape of the acceleration Fourier spectrum curve and the predominant frequency of the liquefied site change greatly under the action of moderate and stronger earthquakes than those of nonliquefied sites. The above results show that, under the action of horizontal earthquakes, the characteristics of sand have a great impact on its own spectral characteristics.

3.1.3. Comparative Analysis of Structural Strain. In order to figure out the influence of unsaturated sand site and saturated sand site on the structural strain under earthquake, corresponding strain gauges were arranged in the middle of the tunnel section before the test. The locations of strain gauges are shown in Figure 6. The structural strain peaks of the two groups of tests are shown in Table 5.

The following can be seen from Table 5: (1) The strain peak value of each measuring point in test 1 and test 2 increased with the increase of EL wave input amplitudes. Under the action of EL wave with the same amplitude and at the same measuring point, the strain peak value of test 2 was larger than that of test 1 . This is because the density of the soil layer in test 2 was larger than that of test 1 (Table 2), and the soil pressure coefficient increased when the sand became muddy water after liquefaction. (2) In tests 1 and test 2, the peak strain on the upper part of the structure was larger than the lower parts, and the peak value of S2 and S5 was larger than the other measuring points. Therefore, the upper part of the tunnel, especially the middle wall and the side wall, is the weak position of the structure.

In order to better reflect the growth process of structural strain in the test, the growth rate of measuring point strain is used in this paper, which is defined as the ratio of the strain peak value of structural measuring points under the action of EL-2 wave and EL-3 wave to that of EL-1 wave. The formula of strain growth rate is

$$
\mathrm{SGR}=\frac{S(j)-S(i)}{S(i)},
$$

where $S(i)$ is the strain peak under the action of EL-1 and $S(j)$ is the strain peak under the action of EL-2 wave and EL3 wave.

The strain growth rate of the structures under the EL-2 wave and EL-3 wave in the two groups is shown in Figure 10. The following can be seen: (1) The strain growth rate increased with the increase of the input amplitude of the EL wave. (2) The rate of measuring point S5 was the highest, while that of S4 was the lowest. (3) Under the action of EL-2 waves, the rate of each point in the two groups was similar. However, under the action of EL-3 wave, the strain growth rates in test 1 were significantly higher than those of test 2 , which may be due to the large nonlinear strain produced in test 2 under the action of EL-2 wave. With the increase of ground motion amplitude, the structural stress was redistributed, and the nonlinear strain at the measuring point decreased somewhat. In test 1 , under the action of EL-2 wave, the strain peak value at the measuring point of the structure was small, and the strain was still in an elastic state. With the increase of the ground motion amplitude, a large nonlinear strain was generated at the measuring point.

The above results indicate that the characteristics of sand have few effects on the strain growth rate of the structures under small and medium earthquakes, while under strong earthquakes, they may have a significant effect. There is a spatial effect on the distribution of structural strain, and seismic waves with different peak values also affect the growth rate of structural strain.

3.2. Comparisons and Analysis of Test Results in Case 2. Case 2 was the comparative analysis of test 1 and test 3 , aiming to explore the influence of homogeneous soil layer and heterogeneous soil layer on the seismic response of immersed tunnels when they are distributed along the longitudinal direction of the immersed tunnels.

3.2.1. Contrast Analysis of Acceleration Amplification Coefficient of Soil Layer. To study the influence of homogeneous soil layer and heterogeneous soil layer on seismic wave propagation when distributed along the longitudinal direction of the immersed tunnels, the acceleration amplification factor of the soil layer is also used for description. The specific method is the same as that of working condition 1 . The acceleration amplification factor of the soil layer in the two groups of tests is shown in Figure 11.

The following can be seen from Figure 11: (1) Under the action of EL wave, the acceleration amplification coefficients of the soil layer in test 1 and test 3 both increased with the decrease of the buried depth of the soil layers, but the acceleration amplification coefficient range of the soil layer in test 3 was larger than that of test 1. (2) When the input amplitude of EL wave was $0.1 \mathrm{~g}, 0.2 \mathrm{~g}$, and $0.4 \mathrm{~g}$, the variation law of the coefficients at the same measuring point in test 1 and test 3 varied. For example, the coefficients of A4 in test 1 were $1.62,1.38$, and 1.21 , respectively, which decreased with the increase of the input amplitude, while those in test 3 were $1.43,1.62$, and 1.81 , respectively, which increased with the increase of the input amplitude of ground motion. Therefore, the failure probability of soil layers and structures caused in test 3 was higher than that of test 1 under the action of a medium-strong earthquake.

The above results suggest that the distribution of soil layers with different properties also influences the propagation of seismic waves in the sites (For instance, the acceleration amplification effect of the soil layer of test 1 at the same measurement point was significantly different from that of test 3).

\subsubsection{Comparative Analysis of Fourier Spectrum of Soil} Acceleration. To explore the influence of homogeneous soil layer and heterogeneous soil layer on the dynamic characteristics of site soil when they are distributed along the longitudinal direction of the immersed tunnels, the 
TABLE 5: Strain peak of structure under EL wave $(\mu \varepsilon)$.

\begin{tabular}{lcccccc}
\hline \multirow{2}{*}{ Measuring point } & \multicolumn{3}{c}{ Test 1 } & & Test 2 \\
& EL-1 & EL-2 & EL-3 & EL-1 & EL-2 & EL-3 \\
\hline S1 & 13.5 & 23.1 & 66.8 & 22.60 & 36.80 & 70.74 \\
S2 & 22.4 & 31.6 & 85.3 & 33.87 & 51.13 & 100.89 \\
S3 & 8.6 & 14.6 & 45.9 & 21.71 & 34.01 & 50.55 \\
S4 & 13.5 & 15.6 & 46.6 & 28.98 & 41.25 & 60.87 \\
S5 & 13.3 & 19.9 & 80.5 & 28.58 & 42.97 & 108.15 \\
S6 & 10.1 & 15.5 & 45.0 & 19.17 & 27.14 & 36.37 \\
\hline
\end{tabular}

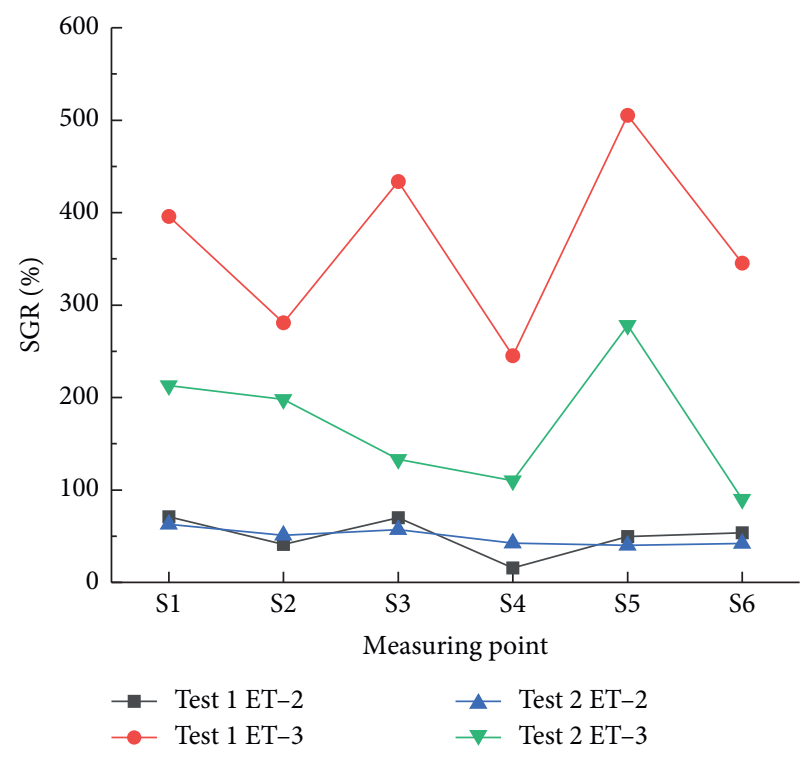

FIgURe 10: Case 1 strain growth rate of structure.

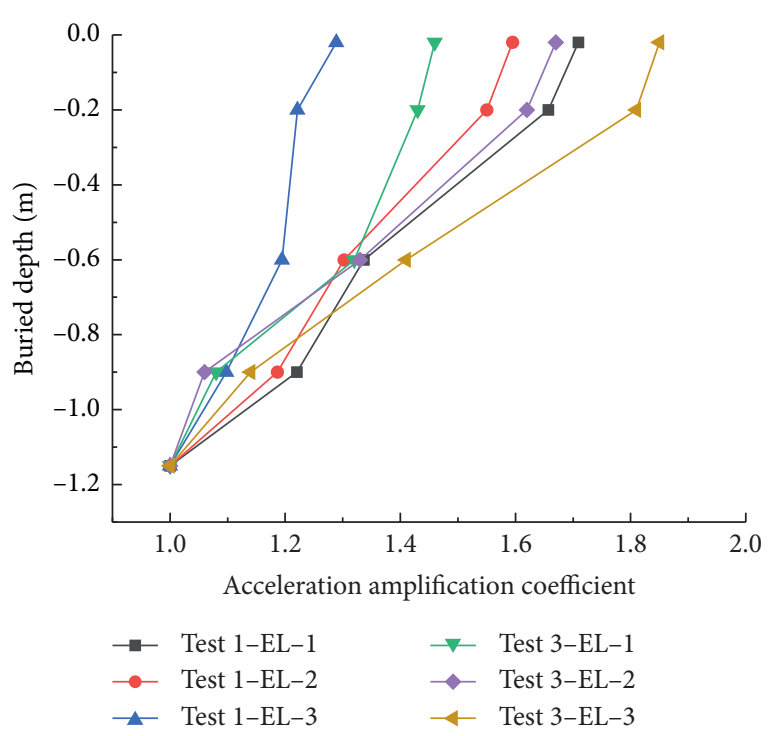

FIgURE 11: Case 2 acceleration amplification factor of soil layer.

acceleration time histories of each measuring point in test 1 and test 3 are, respectively, Fourier-transformed for the corresponding acceleration Fourier spectra. Only the acceleration Fourier spectra of each measuring point under
EL-3 seismic wave input in two groups of tests are contrasted and analyzed. Please refer to Figure 9(a) for the acceleration Fourier spectra of each measuring point in test 1 and Figure 12 for the acceleration Fourier spectra of each measuring point in test 3 .

From Figures 9(a) and 12, the following can be concluded: (1) The amplitude of the acceleration Fourier spectrum at each measuring point in the soil layer in test 1 and test 3 changed consistently, increasing with the buried depth of the soil layers descending. (2) The amplitude in test 3 was larger than that of test 1. (3) The acceleration Fourier spectrum frequency in test 1 and test 3 mainly fluctuated between $0 \mathrm{~Hz}$ and $20 \mathrm{~Hz}$, and the low-frequency component $(0 \sim 8 \mathrm{~Hz})$ was gradually amplified in the upward propagation process of seismic waves. The acceleration Fourier curve shape in the two groups was approximately consistent, but the frequency components of soil layers in test 3 were richer than those in test 1 on the whole.

3.2.3. Comparative Analysis of Structural Strain. To study the influence of homogeneous soil layer and heterogeneous soil layer on the internal forces of the structure when they are distributed along the longitudinal direction of immersed tunnels, the strain measuring points in the middle of the tunnel sections are contrasted and analyzed. The positions of the strain gauges are shown in Figure 6. The effective strain peaks are shown in Table 6 except for the data collected by S1, S2, and S3 because of damage.

The following can be seen from Table 6: (1) The strain peak value of each measuring point in test 1 and test 3 increased with the increase of the input amplitude of EL wave. For example, in test 1 , when the local seismic wave input amplitude increased from $0.2 \mathrm{~g}$ to $0.4 \mathrm{~g}$, the strain amplitude of $\mathrm{S} 4$ increased from 15.6 to 46.6 , and, in test 3 , the amplitude increased from 30.3 to 73.1. (2) In tests 1 and 3, the strain peak at the upper part of the structure was larger than that of the lower parts. For example, in test 1, under the EL-1 wave input, the strain peak value of measurement point S5 was 13.3, with that of point S6 being 10.1 , and in test 3 , the value of $S 5$ was 15.2 , with that of $S 6$ being 13.4. Under the input of EL-2 and EL-3 waves, the same results were obtained. (3) The strain peak value in test 3 was larger than that in test 1 at the same measuring point under the same seismic input. For example, under the EL-1 wave input, the strain peak value of measuring point $S 5$ in test 3 was 15.2, while that in test 1 was 13.3. The other measuring points shared the same rule. This shows that, under the same earthquake, the failure probability of the structure in test 3 is larger than that in test 1 . Due to the large displacement difference of different soil layers in the vibration process, the relative displacement difference of the structure is relatively large, so the failure probability of the structure may also rise.

3.3. Comparisons and Analysis of Test Results in Case 3 [22]. Case 3 was the comparative analysis of test 2 and test 4 , aiming at the influence of tunnel stiffness on the seismic response of the immersed tunnels. 


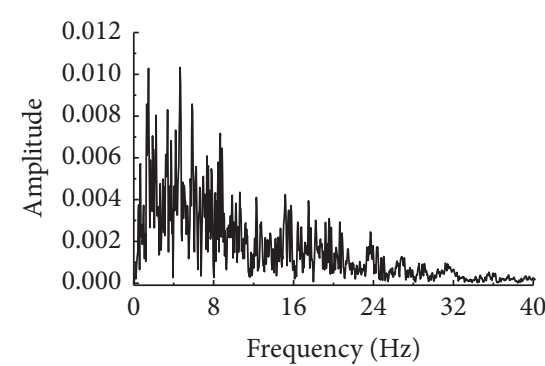

(a)

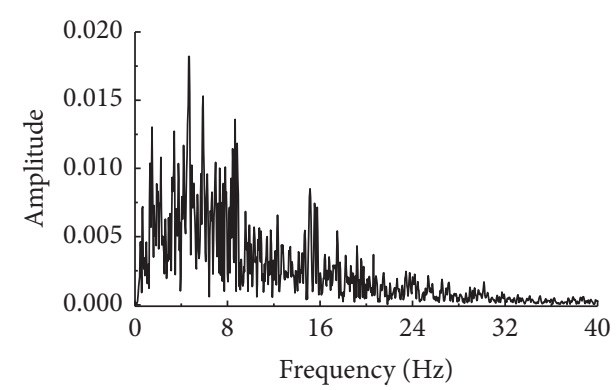

(d)

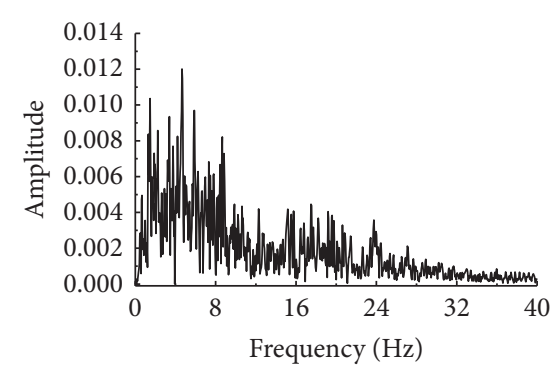

(b)

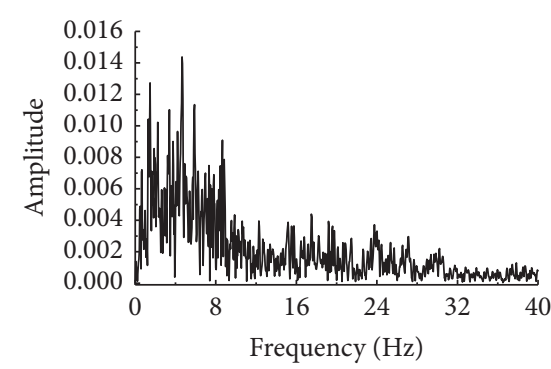

(c)

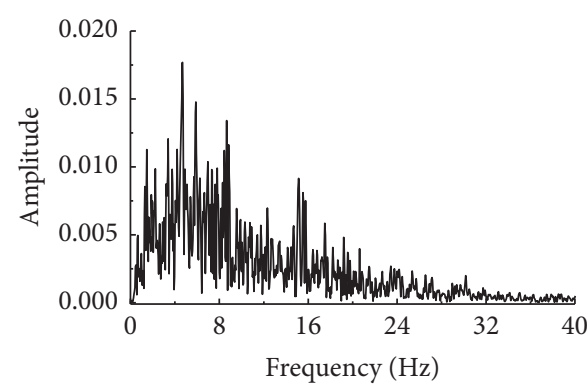

(e)

Figure 12: Test 3 acceleration Fourier spectrum of soil layer. (a) A1. (b) A2. (c) A3. (d) A4. (e) A5.

TABLE 6: Strain peak of structure under EL wave $(\mu \varepsilon)$.

\begin{tabular}{lcccccc}
\hline \multirow{2}{*}{ Measuring point } & & Test 1 & & Test 3 \\
& EL-1 & EL-2 & EL-3 & EL-1 & EL-2 & EL-3 \\
\hline S1 & 13.5 & 23.1 & 66.8 & & & \\
S2 & 22.4 & 31.6 & 85.3 & & & \\
S3 & 8.6 & 14.6 & 45.9 & & & \\
S4 & 13.5 & 15.6 & 46.6 & 17.7 & 30.3 & 73.1 \\
S5 & 13.3 & 19.9 & 80.5 & 15.2 & 30.2 & 99.1 \\
S6 & 10.1 & 15.5 & 45.0 & 13.4 & 28.1 & 48.9 \\
\hline
\end{tabular}

3.3.1. Contrast Analysis of Acceleration Amplification Coefficient of Soil Layer. To explore the influence of tunnel stiffness on the propagation of seismic waves in the soil layers, the acceleration amplification factor of the soil layers is also applied for description. The specific method and the location of the observation surface are the same as those of case 1, as shown in Figure 13.

Figure 13 illustrates that the acceleration amplification factors in test 4 ranged from 0.6 to 2.0, which were larger than those of test 2. Due to the large rigidity of the tunnel, the seismic response of the soil layer nearby was restrained, and the acceleration of the soil layer reduced (the peak accelerations of $\mathrm{A} 3$ and $\mathrm{A} 4$ were smaller than that of A1). Under the joint action of tunnel stiffness and weight, although the pore pressure of the soil layers increased with the increase of seismic wave input amplitude, it did not reach liquefaction, so the acceleration of the surface soil layer (measuring point A5) increased. Therefore, the acceleration amplification factor of the soil layers in test 4 first decreased and then increased with the decrease of the soil depth. The rule of the acceleration amplification factor in test 2 resembled case 1 , which will not be repeated here.
Comparing the acceleration amplification coefficient curves of the two groups of tests, it can be seen from Figure 13 that, under the EL-2 and EL-3 wave inputs, the variation law of acceleration amplification coefficient of the soil near the tunnel is the same, but the causes are different. For example, in test 2 , the acceleration amplification factor of the soil layer decreased with the decrease of the buried depth. It was mainly due to the liquefaction of the soil layer, which reduced the acceleration of the soil layer. In test 4 , the response of the soil layer was restrained due to the larger stiffness of the tunnel, which reduced the acceleration. The acceleration amplification coefficients (A3 and A4) of the soil layer near the tunnel in test 4 were smaller than those in test 2 .

The above results demonstrate that the stiffness of the tunnel significantly influences the seismic wave propagation in the sites.

\subsubsection{Comparative Analysis of Fourier Spectrum of Soil} Acceleration. To learn about the influence of the tunnel stiffness on the site soil dynamic characteristics, the soil acceleration time-history curves in test 2 and test 4 went through Fourier transformation before analysis. Because of the limited writing space, only the measuring points under EL-3 ground motion input are analyzed here. The acceleration Fourier spectrum of each measuring point in test 4 is shown in Figure 14, and that in test 2 is shown in Figure 9(a).

The following can be seen from Figures 9(a) and 14: (1) In test 4 , the acceleration Fourier spectrum amplitudes of measuring points A3 and A4 were smaller than those of test 2 , which is due to the lower vibration amplitude of the soil layers nearby the structure resulting from the larger restraints produced by the stiffer structures in test 4 . (2) The 


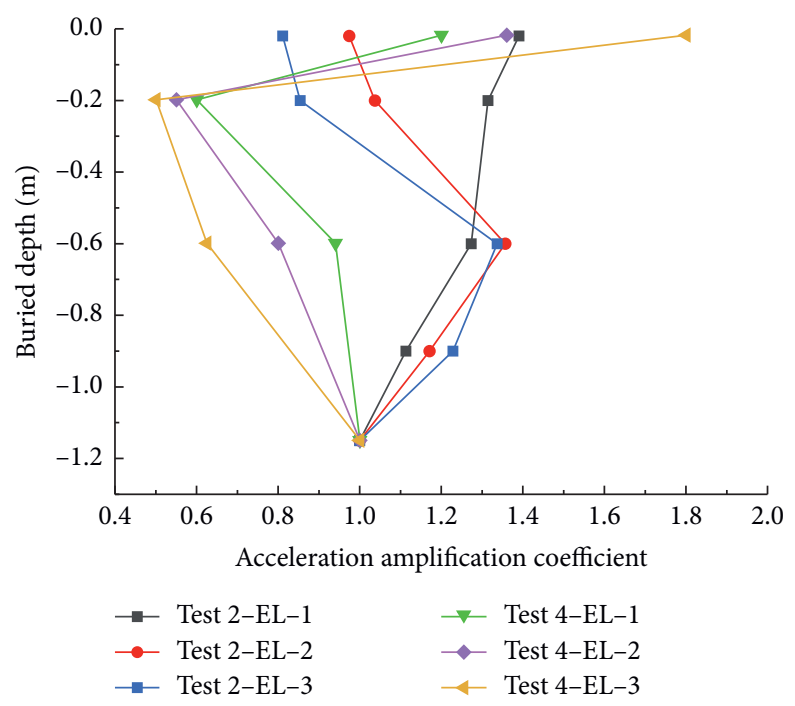

Figure 13: Case 3 acceleration amplification factor of soil layer.

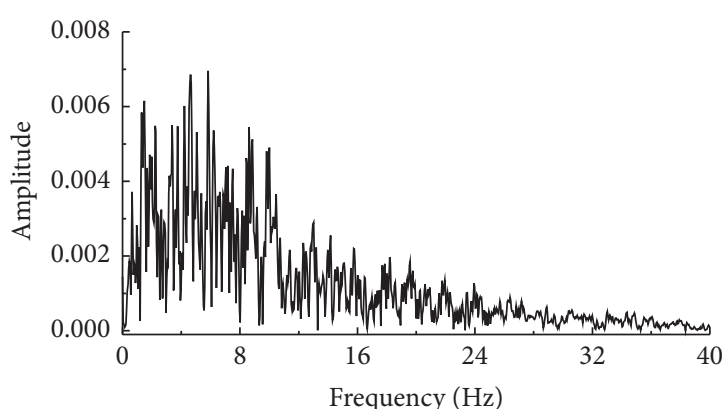

(a)

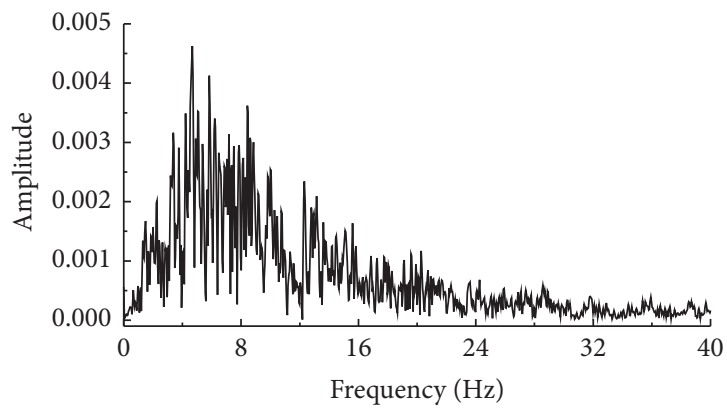

(c)

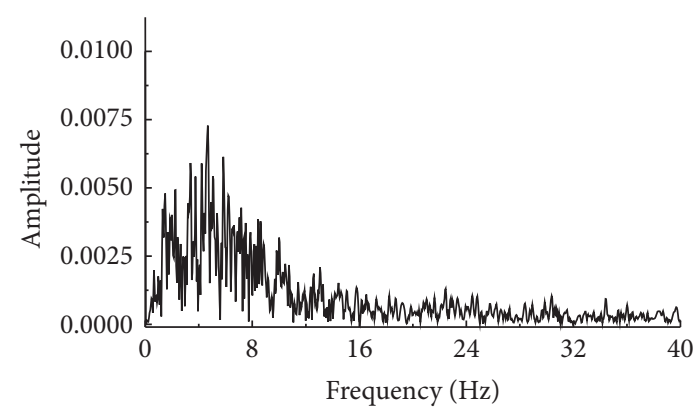

(b)

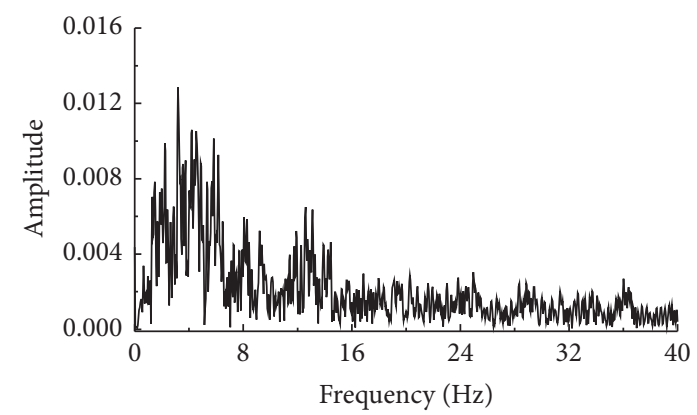

(d)

FIgURE 14: Acceleration Fourier spectrum of test 4 soil layer under EL-3 ground motion input. (a) A1. (b) A3. (c) A4. (d) A5.

Fourier spectrum amplitude of acceleration at A5 in test 4 was larger than that in test 2 . That is, because the vibration amplitude of the soil layers near A5 reduced due to the liquefaction of the soil layer at A5 in test 2. (3) When the seismic wave propagated upward, obvious low-frequency concentration and amplification effect occurred in the frequency spectrum of test 2 . For example, the predominant frequency of the acceleration Fourier spectrum of measuring points $\mathrm{A} 4$ and $\mathrm{A} 5$ reduced (from $6 \mathrm{~Hz}$ to about $2 \mathrm{~Hz}$ ) compared with A1. This is because the liquefaction of saturated sand reduced the effective stiffness and made the predominant frequency move from high to low. However, in test 4 , the predominant frequency of the soil layers changed minimally except for that of A5, which reduced evidently. (4) The shapes of the acceleration Fourier curves of A4 and A5 in test 2 were quite different from those of $\mathrm{A} 1$ and $\mathrm{A} 3$, but the shape side of the acceleration Fourier curve of each measuring point in test 4 was approximately the same.

From the above analysis, it can be concluded that the tunnel stiffness can affect not only the acceleration Fourier 
TABLE 7: Strain peak of structure under EL wave $(\mu \varepsilon)$.

\begin{tabular}{lcccccc}
\hline \multirow{2}{*}{ Measuring point } & \multicolumn{3}{c}{ Test 2 } & \multicolumn{3}{c}{ Test 4 } \\
& EL-1 & EL-2 & EL-3 & EL-1 & EL-2 & EL-3 \\
\hline S1 & 22.60 & 36.80 & 70.74 & 14.17 & 19.94 & 24.67 \\
S2 & 33.87 & 51.13 & 100.89 & 18.20 & 27.13 & 45.01 \\
S3 & 21.71 & 34.01 & 50.55 & 9.23 & 14.86 & 18.41 \\
S4 & 28.98 & 41.25 & 60.87 & 11.51 & 15.41 & 26.24 \\
S5 & 28.58 & 42.97 & 108.15 & 15.38 & 21.83 & 25.27 \\
S6 & 19.17 & 27.14 & 36.37 & & & \\
\hline
\end{tabular}

spectrum amplitude and the predominant frequency of the soil layer nearby but also the shape of the acceleration Fourier curve.

3.3.3. Comparative Analysis of Structural Strain Analysis. In order to explore the influence of tunnel stiffness on its internal force under earthquake action, the strain measuring points in the middle of the tunnel sections of the two groups are analyzed and compared. The locations of the strain gauges are shown in Figure 6(b). The effective strain peaks are shown in Table 7 except for those collected by the S6 strain gauge in test 4 , which was damaged in the test.

The following can be seen from Table 7:

(1) The peak strain value of each measuring point in test 2 and test 4 increased with the increase of the input amplitude of EL wave. For example, in test 2, when the input amplitude of EL wave increased from $0.2 \mathrm{~g}$ to $0.4 \mathrm{~g}$, the strain peak value of measuring point $\mathrm{S} 2$ increased from 51.13 to 100.89 , and, in test 4 , the value of S2 increased from 27.13 to 45.01 .

(2) The peak strain in the upper part of the structure in tests 2 and 4 was larger than that in the lower part. For example, under the input of the EL-1 wave, the strain peak value of S2 was 33.87 with that of S1 being 22.6 in test 2. Similarly, the peak values of S4 and S5 were also greater than those of S3 and S6.

(3) The strain peak value of test 2 was larger than that of test 4 at the same measuring point. For example, the strain peak value of S2 in test 2 was 51.13, while the strain peak value of S2 in test 4 was 27.13. This rule worked at the other points. This shows that the tunnel in test 2 is more amenable to the movement of the surrounding soil layers.

In order to better reflect the growth process of the structural strain in the test, the growth rate of strain at the measuring points is also used to describe it, of which the definition is the same as that in case 1 . The growth rates of the two groups of tests under excitations EL-2 and EL-3 are shown in Figure 15. The following can be seen from Figure 15 as follows: (1) The strain growth rate of the structure in the two groups increased with the increase of the input amplitude of EL wave. (2) Under the excitation EL-2 wave, there was no significant difference in strain growth rate between test 2 and test 4, while under excitation EL-3 wave, the strain growth rate of multiple measuring points in test 2 was significantly higher than that in test 4 , in which the growth rates of $\mathrm{S} 1$ and $\mathrm{S} 5$ in test 2 were the fastest, while the growth rate of $S 4$ was the lowest. In test 4 , the growth rate of S2 was the fastest, while that of S5 was the lowest.

The above results show that, under the small or moderate earthquakes, the stiffness of the structures has little influence on the strain growth rate of the structures, while under the strong earthquakes, it significantly influences the strain growth rate. There is spatial effect on the distribution of structural strain, and the seismic wave with different peak values also has influence on the growth rate of the structural strain.

For more information on this chapter, please refer to shaking table test study on flexible and rigidly immerged tube tunnel in liquefiable soil layer [22].

3.4. Comparison and Analysis of Test Results in Case 4. Case 4 is the comparative analysis of test 2 and test 5 , aiming at the influence of the earthquake input direction on the seismic response of the immersed tunnels.

3.4.1. Comparative Analysis of Fourier Spectrum of Soil Acceleration. In order to explore the influence of the input direction of seismic wave on the dynamic characteristics of the site soil, the soil acceleration time-history curves in tests 2 and 5 went through Fourier transformation before analysis. Due to the limited writing space, only the acceleration Fourier spectra of the measuring points under EL-2 and EL3 wave inputs in the two tests are contrasted and analyzed, as shown in Figures 16 and 17.

Figures 16 and 17 illustrate the following: (1) In the two groups of tests, the amplitude of the acceleration Fourier spectrum at the same position increased with the increase of the input amplitude of EL wave. (2) In the two groups, the amplitude increased with the decrease of soil depth. (3) When the seismic wave input in the horizontal direction propagated upward, the action of the low-frequency part of the seismic wave in test 2 increased (the amplitude of the $2-7 \mathrm{~Hz}$ frequency part in the Fourier spectrum was gradually amplified), while that of the high-frequency part decreased. For vertical input seismic waves propagating upward, the action of the high-frequency part of the seismic wave in test 5 increased (the amplitude of the $10-20 \mathrm{~Hz}$ frequency part in the Fourier spectrum was gradually amplified), while the low-frequency part decreased. This shows that, under the vertical ground motion input, the field soil can reduce the vibration of the structures with a long natural vibration period but can enhance the vibration of the structures with a short natural vibration period. Under the horizontal earthquake, the result is quite the opposite. It can be seen that, under the seismic wave with different input directions, the natural frequency of the site is different, so the causes of structural damage vary. Therefore, the input direction of seismic wave should be considered in the design of the structures.

3.4.2. Comparative Analysis of Tunnel Structural Strain Analysis. To study the influence of the input direction of seismic wave on the tunnel internal forces, the strain 


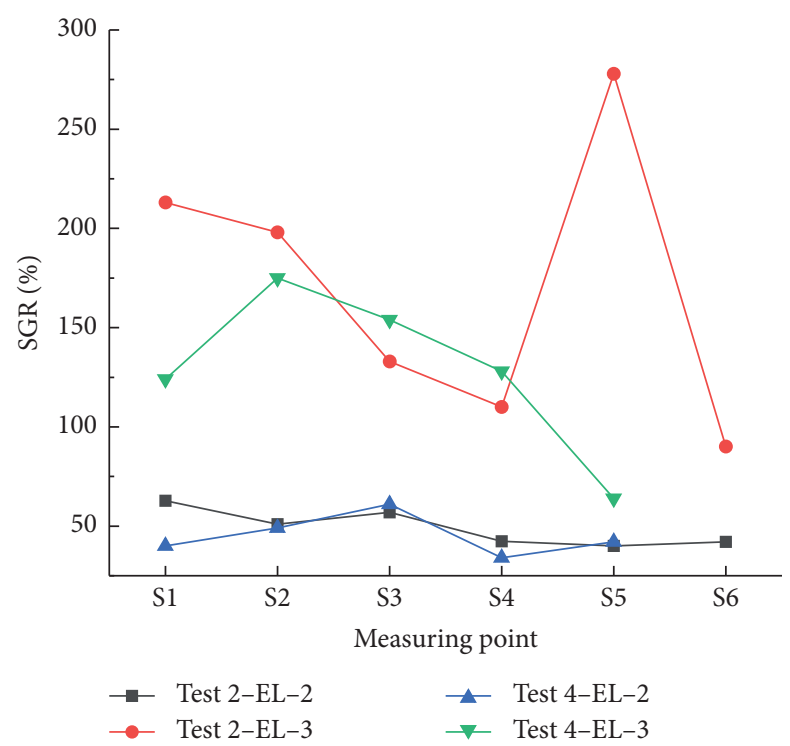

Figure 15: Case 3 strain growth rate of structure.
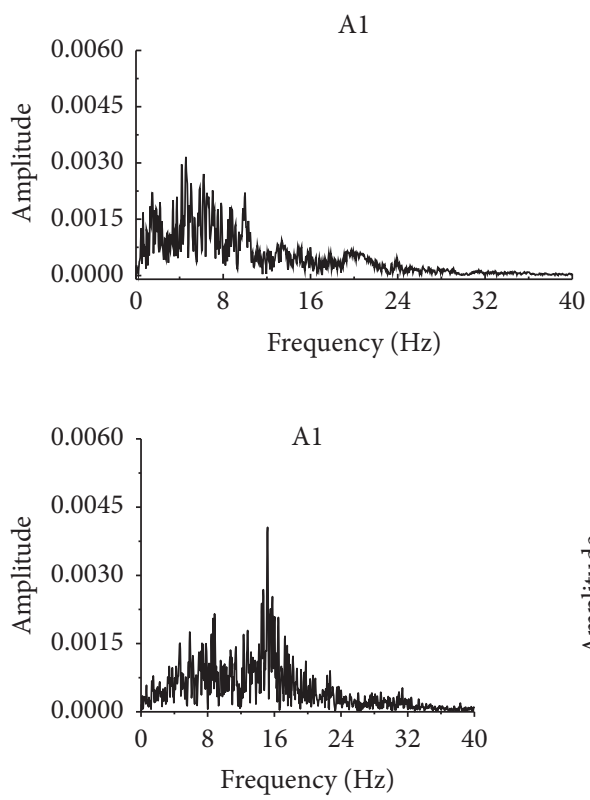

A4

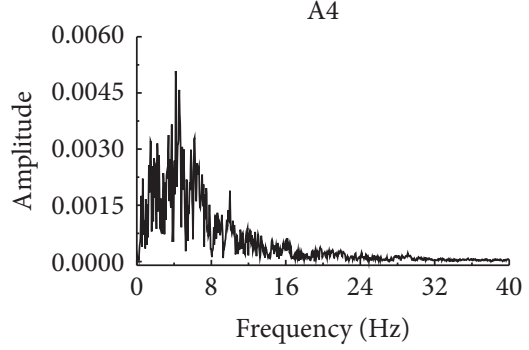

(a)

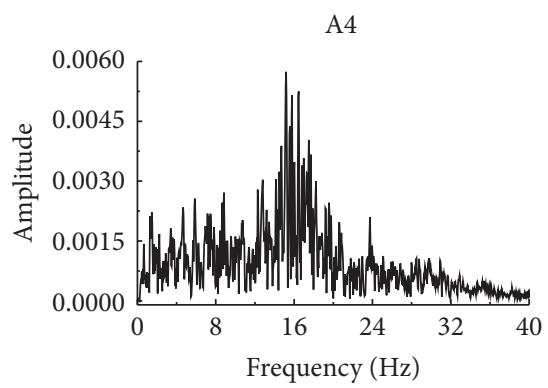

A5

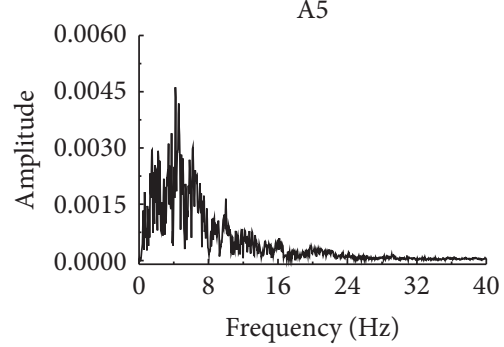

A5

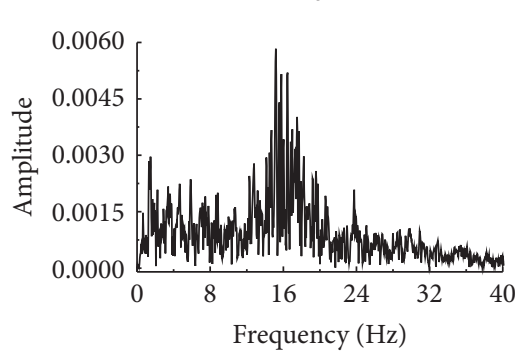

(b)

Figure 16: Acceleration Fourier spectrum of test 2 and test 5 soil layers under El-2 input. (a) Test 2. (b) Test 5.

measuring points in the middle of the tunnel sections of the two groups are analyzed and compared. The locations of strain gauges are shown in Figure 6. The effective strain peaks in test 5 are shown in Table 8 except for the data of the S3 strain gauge due to damage.

Table 8 illustrates the following: (1) The strain peak value of each measuring point in test 2 and test 5 increased with the input amplitude of EL wave increasing. For example, when the input amplitude of EL wave increased from $0.2 \mathrm{~g}$ to $0.4 \mathrm{~g}$, the strain amplitude of S2 in test 2 increased from 51.13 to 100.89 and that in test 5 increased from 7.9 to 10.2 . (2) Under the action of EL wave with the same amplitude, the strain peak value of the structure in test 2 was larger than that in test 5 at the same position of the two groups. This suggests that, under the action of seismic wave with the same amplitude, the strain peak value of the structures caused by the horizontal earthquake input is larger than that of the vertical one. (3) The peak strain of the upper part of the structures in test 5 was smaller than that of the lower part, while in test 2 it was the opposite. For example, the peak 

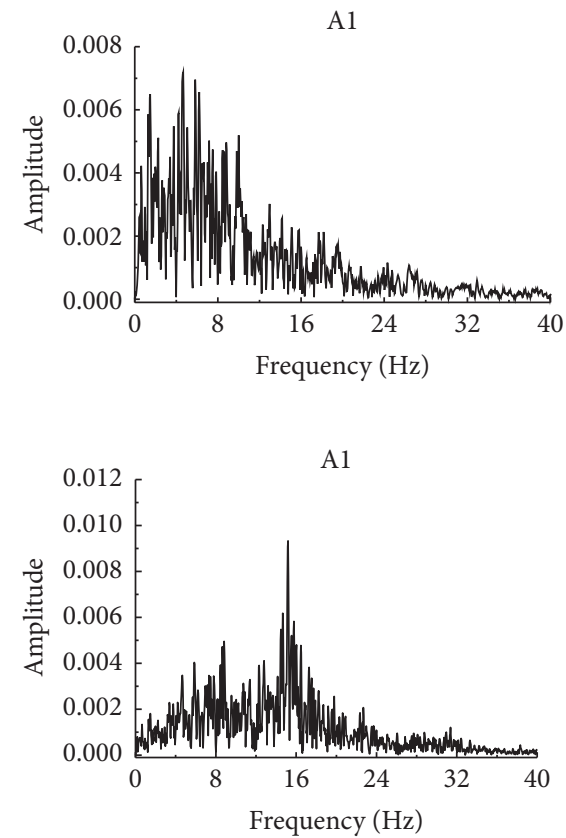

A4

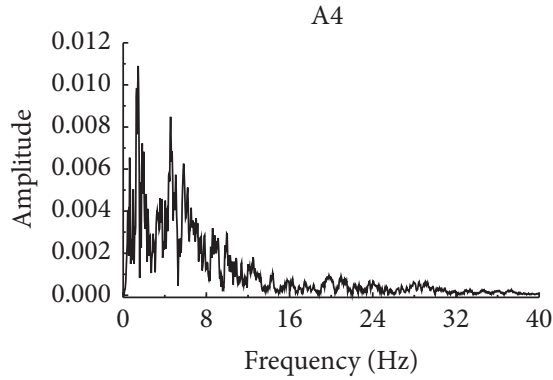

(a)

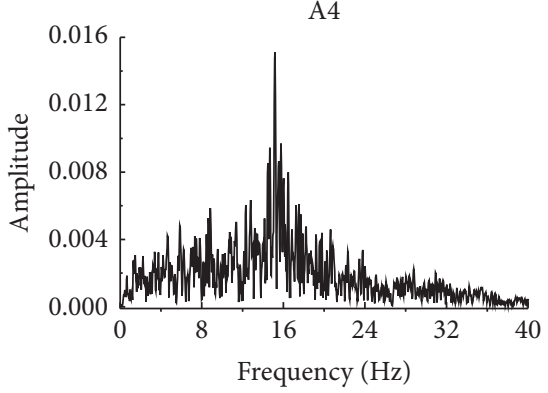

(b)

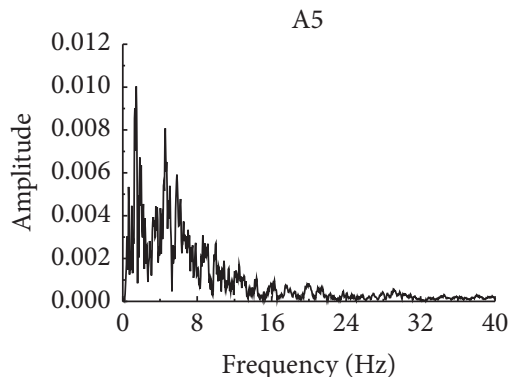

A5

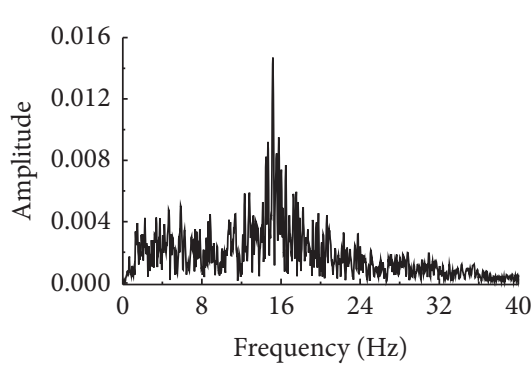

Figure 17: Acceleration Fourier spectrum of test 2 and test 5 soil layers under El-3 input. (a) Test 2. (b) Test 5.

TABLE 8: Strain peak of structure under EL wave $(\mu \varepsilon)$.

\begin{tabular}{lcccccc}
\hline \multirow{2}{*}{ Measuring point } & \multicolumn{3}{c}{ Test 2 } & \multicolumn{3}{c}{ Test 5 } \\
& EL-1 & EL-2 & EL-3 & EL-1 & EL-2 & EL-3 \\
\hline S1 & 22.60 & 36.80 & 70.74 & 6.4 & 10.6 & 18.1 \\
S2 & 33.87 & 51.13 & 100.89 & 4.8 & 7.9 & 10.2 \\
S3 & 21.71 & 34.01 & 50.55 & - & - & - \\
S4 & 28.98 & 41.25 & 60.87 & 5.6 & 8.3 & 12.2 \\
S5 & 28.58 & 42.97 & 108.15 & 8.1 & 10.8 & 18.2 \\
S6 & 19.17 & 27.14 & 36.37 & 9.3 & 12.4 & 27.1 \\
\hline
\end{tabular}

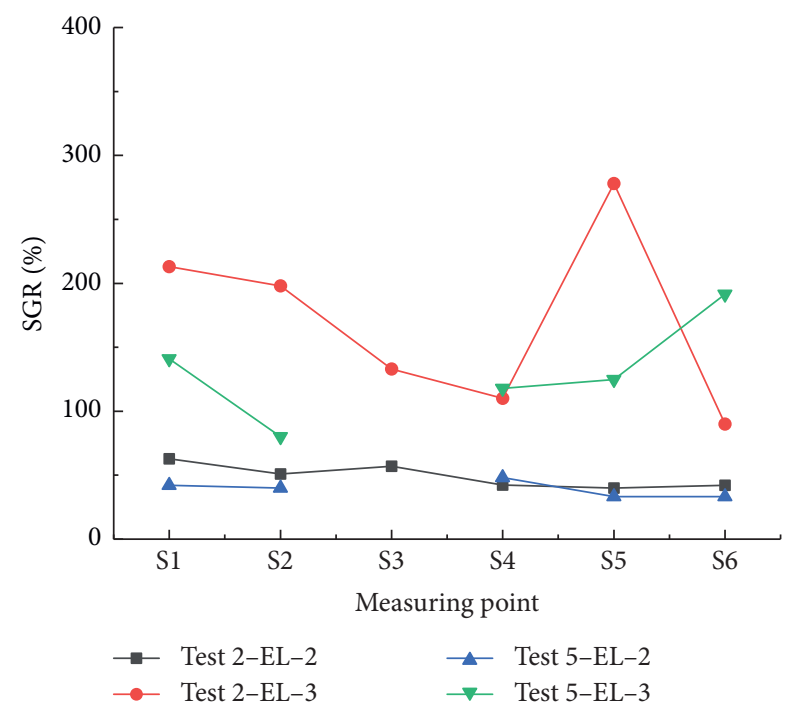

FIgURE 18: Case 4 strain growth rate of structure.

strain at points $S 5$ and $S 2$ in test 5 was smaller than that at S6 and S1. It can be seen from the above analysis that the seismic wave input direction has a great influence on the internal force of the structures, and different seismic wave input directions may cause different structural destruction mechanisms.

In order to better reflect the growth process of the structural strain in the test, the growth rate of strain at the measuring points is also used to describe it, of which the definition is the same as that of case 1. The strain amplitude growth rate of the two groups under the working conditions EL-2 and EL-3 is shown in Figure 18. The following can be seen from Figure 18: (1) The strain growth rate of the structures in the two groups increased with the input amplitude of the EL wave increasing. (2) Under the excitation EL-2 wave, the structural strain peak at the same measuring point in test 2 was much larger than that in test 5, but the strain peak growth rate side was close. (3) Under the excitation EL-3 wave, the strain growth rate of multiple measuring points in test 2 was significantly higher than that in test 5 . The growth rate of measuring point 5 in test 2 and that of point 6 in test 5 were the largest.

The above results indicate that the seismic wave input direction has little effect on the strain growth rate of the structures under small and medium earthquakes but may affect it significantly under strong earthquakes. There is also a spatial effect on the structural strain distribution, and seismic waves with different peak values also have an effect on the structural strain growth rate.

\section{Conclusions}

Through the shaking table tests, the influence of five aspects on the seismic response of the immersed tunnels, the unsaturated sand site, saturated sand site, longitudinal 
nonuniform site, tunnel stiffness, and ground motion input direction, is discussed. Through the analysis of the test results, the following conclusions are obtained:

(1) Site soil characteristics, structural stiffness, and seismic wave input direction may influence the development of soil layer acceleration to some extent, especially saturated sand and large structural stiffness.

(2) Under the horizontal ground motion input, the changes in the Fourier spectra of the soil layers in tests 1 to 4 were the same. In the four tests, the lowfrequency part was amplified when the seismic wave propagated upward in the soil layers, while the highfrequency part reduced. The result was the opposite under the vertical seismic wave input (the low-frequency part was reduced, while the high-frequency part increased).

(3) Sand liquefaction can not only move the excellent frequency of the soil layer from high to low but also change the shape of the acceleration Fourier spectrum curve. The larger structural stiffness may partially hinder the liquefaction of the soil layer and influence the shape of the acceleration Fourier spectrum curve of the nearby soil layers to some extent.

(4) The influence of site conditions, structural stiffness, and seismic wave input direction on the internal force growth of the structures is significantly different. The internal force of the structures in test 2 was the largest, while that in test 5 was the smallest.

(5) The peak value of the structural strain in the 5 groups of experiments increased with the increase of the ground motion input amplitude, but the structural strain growth rates of the 5 groups of experiments were different. Under the action of horizontal earthquakes, the peak strain of the upper part of the center column and the side walls of the structure is larger than those of the other locations. However, under the vertical seismic wave, the locations with the peak strain are the opposite.

\section{Data Availability}

The data used to support the findings of this study are available from the corresponding author upon request.

\section{Conflicts of Interest}

The authors declare that they have no conflicts of interest regarding the publication of this paper.

\section{Acknowledgments}

This work was supported by the National Natural Science Foundation of China (Grant nos. 51808259, 51438004, and 51408566) and Colleges Youth Innovative Talents Project of
Guangdong Province (no. 2019KQNCX147 and 2020KTSCX138).

\section{References}

[1] M. Wang, Tunnel and Underground Engineering Technology and Development, Northern Jiaotong University Press, Beijing, China, 2004.

[2] M. Wang, "Construction scheme of Taiwan strait subsea railway tunnel," Journal of Chongqing Jiaotong University (Natural Science), vol. 30, no. S2, pp. 1113-1120, 2011.

[3] C. Sun, B. Jingshan, W. Qi et al., "Status and prospect of seismic research on underground structures," World Earthquake Engineering, vol. 25, no. 6, pp. 94-89, 2009.

[4] C. H. Dowding and A. Dozen, "Damage to rock tunnels from earthquake shaking," Journal of the Geotechnical Engineering Division, vol. 104, no. GT2, pp. 175-191, 1978.

[5] Z. Chen, "Development of dynamic centrifugal model test system for metro tunnel in cohesive soil foundation," Master's thesis, Tsinghua University, Beijing, China, 2005.

[6] N. M. Newmark, "Problems in wave propagation in soil and rock," in Proceedings of the International Symposium on Wave Propagation and Dynamic Properties of Earth Materials, University of New Mexico Press, Albuquerque, NM, USA, August 1967.

[7] T. R. Kuesel, "Earthquake design criteria for subways," Journal of the Structural Division, vol. 95, no. ST6, pp. 1213-1231, 1969.

[8] Z. Dong, J. Wang, and D. Zhao, "Solving method of soil spring stiffness of shallow shield tunneling," Journal of Civil, Architectural and Environmental Engineering, vol. 35, no. 6, pp. 28-32, 2013.

[9] Z. Dong, J. Wang, and W. Wang, "Response displacement method for seismic analysis of underground structures based on soil layers displacement difference," Vibration and Impact, vol. 32, no. 7, pp. 38-42, 2013.

[10] D. Goerke and K. Willner, "Normal contact of fractal surfaces-Experimental and numerical investigations," Wear, vol. 264, no. 7-8, pp. 589-598, 2008.

[11] W. Yan and K. Komvopoulos, "Contact analysis of elasticplastic fractal surfaces," Journal of Applied Physics, vol. 84, no. 7, pp. 3617-3624, 1998.

[12] H. Huo, Seismic design and analysis of rectangular underground structures, Ph.D. Thesis, Purdue University, West Lafayette, Indiana, 2005.

[13] Y. Guo, X. Jin, and J. Ding, "Parallel computing for seismic response analysis of immersed tunnel with domain decomposition," Engineering Computations, vol. 24, no. 2, pp. 182-199, 2007.

[14] X. L. Jin, Y. Z. Guo, and J. H. Ding, "Three dimensional numerical simulation of immersed tunnel seismic response based on elastic-plastic FEM," Key Engineering Materials, vol. 274-276, pp. 661-666, 2004.

[15] J.-H. Ding, X.-L. Jin, Y.-Z. Guo, and G.-G. Li, "Numerical simulation for large-scale seismic response analysis of immersed tunnel," Engineering Structures, vol. 28, no. 10, pp. 1367-1377, 2006.

[16] S. Okamoto and C. Tamura, "Behaviour of subaqueous tunnels during earthquakes," Earthquake Engineering and Structural Dynamics, vol. 1, no. 3, pp. 253-266, 1972.

[17] G. Chen, X. Zuo, Z. Wang, X. Du, and T. Sun, "Shaking table model test of subway station structure under far field and near field ground motion," Journal of Zhejiang University (Engineering Science), vol. 44, no. 10, pp. 1955-1961, 2010. 
[18] X. Zuo, G. Chen, Z. Wang, X. Du, and H. Gao, "Shaking table test on the seismic response of subway station structure in soft site under near-field and far-field ground motion," Journal of Civil Engineering (Chinese), vol. 43, pp. 299-305, 2010.

[19] X. Zhang, W. Yan, and Y. Chen, "Shaking tables tests for an immersed tunnel model considering wave passage effect," Journal of Vibration and Shock, vol. 37, no. 2, pp. 76-84, 2018.

[20] O. Keizo, S. Toshio, K. Tadashi, and K. Kensei, "Research on streamlining seismic safety Evaluation of underground reinforced concrete Duct-type structures in Nuclear Power stations-part-2," vol. 16, Transactions, SMiRT, Washington, DC, USA, 2001, Experimental Aspects of Laminar Shear Sand Box Excitation Thesis with Embedded RC Models.

[21] Z. Z. Wang, L. Jiang, and Y. Gao, "Shaking table test of seismic response of immersed tunnels under effect of water," Soil Dynamics and Earthquake Engineering, vol. 116, no. 1, pp. $436-445,2019$.

[22] Z. Ouyang, P. Li, J. Cui, R. Luo, and D. Yuan, "Shaking table test study on flexible and rigid immersed tube tunnel in liquefiable soil layer," Mathematical Problems in Engineering, vol. 2020, Article ID 4980549, 16 pages, 2020. 